A GIFT OF PHILANTHROPY TO SCIENCE.

TRANAC LABORATERY FOR THE STUDY OF TUBERCULOSIS.

BY E. R. BALDWIN, M.D.

This institution is situated at Saranac Lake, New York, in the heart of the Adirondack Mountains, and was presented by the late George $\mathrm{C}$ Cooper, of New York, to Dr. E. L. Trudeau, whose name is familiar to visitor in this healthful region. The laboratory, which is the first of its kind, has no commercial features, but is devoted solely to is devoted solely to $r$ In this in tuberculosis. In this it is exceptional being equipped for this special work, and meets a urgent demand in this country, where few facilities are available for suc research, and at a time when medicine is hopefu for the conquest of all infectious diseases; for only by such research in laboratories can we expect to accomplish this end and less-

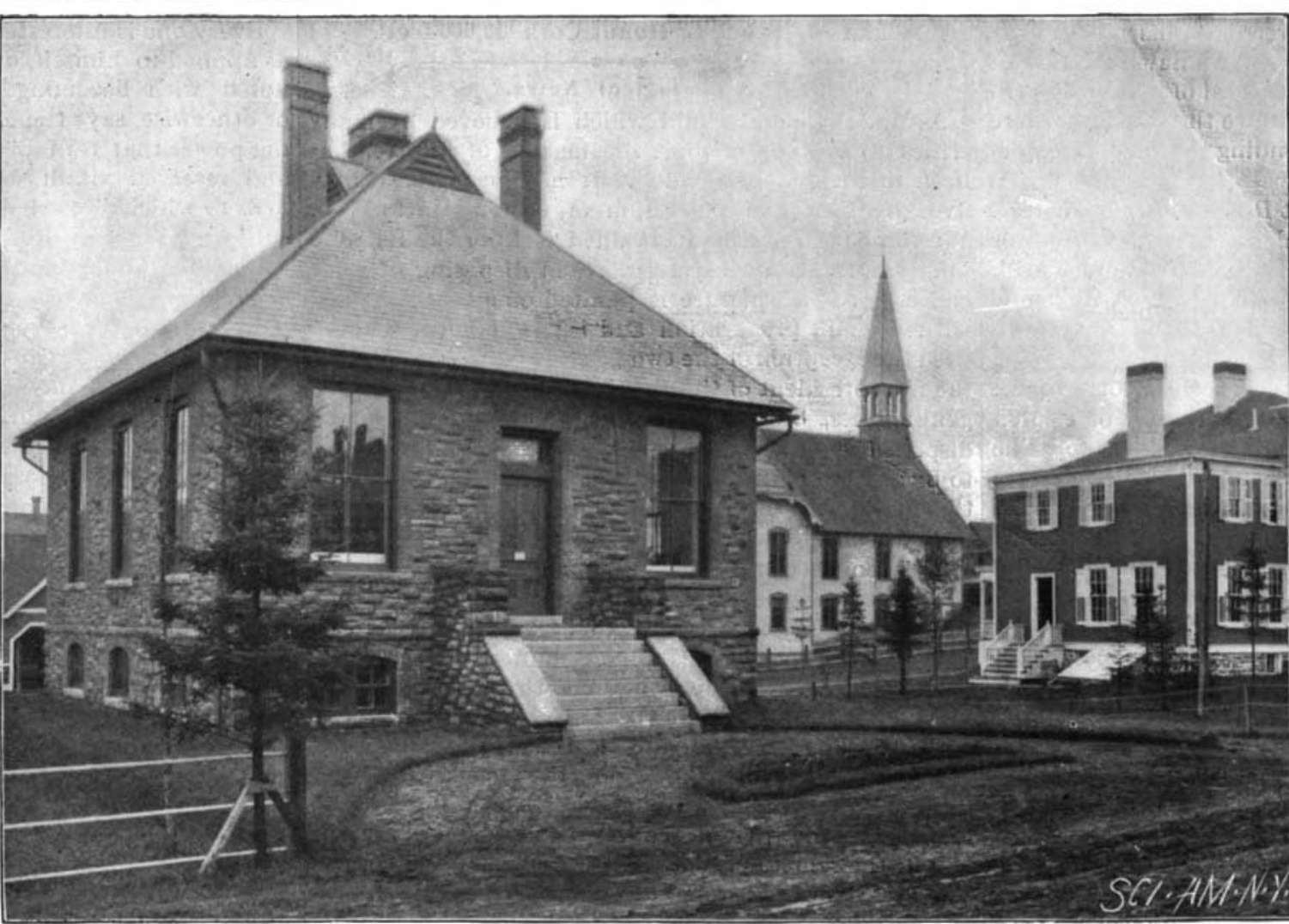

SARANAC LABORATORY FOR THE STUDY OF TUBERCULOSIS

through dust filters; is provided throughou't with electric lights, abumidant water supply and! hot water heating apparatus. This room contains the prin c i pal bacteriological and chemical apparat ms. At the extreme end of this room, on the right, will be noticed one of the incubaters, a nearer view of which tors, a beareen in our large may be seen in our large upright illustration. On the left is seen a private workroom in the distanee. Another view on the ae companying page shows the chemical apparatus and the position of the dry and steam sterilizers in the inclosed hood ; also a simk and work table. On the upper front page is picupper front page is picflasks containing eultures of the tubercle bacill growing on the surface fluids, while the tubes on the $\mathrm{right}$ illustrate its growth on slices of boiled potato and agar. The in cubator, or culture oven, is a metal chamber surrounded by a water jacket rounded by a water jacket and thick asbestes eover-
ing, insuring a aniform

The importance of interlinking research and treat-

ment in tuberculosis had been evident to Dr. Trudeau from the earliest days of the Adirondack Cottage Sanitarium for pulmonary diseases, and with such improvised apparatus and mearer quarters as were the paratus and meager quarters as were the available a series of researches had proved the inportance of such work and given pronise of Cooper, an intelligent observer of the prac-a charity whic also received his benefactions-soon realize that more adequate facilities for investigations here and upon this special theme would give rich promise, not only of important achievements in science, but also of direct and immediate benefit in the practical aim of the sanitarium. This broad conception of the sanitarium. This broad conception or the inportance of establishing a close soon crystallized into a purpose to secure such a relationship here upon a firm and lasting basis. This beneficent and clearly conceived purpose of $\mathrm{Mr}$. Cooper was carrie out with characteristic absence of ostentation, and is only one example of his liberality in the cause of education and in the relief of suffering. His aim was realized dur-

ing his lifetime, and is an

expression of the spirit expression of the spirit which gave to New York the Cooper Institute. MIr. Cooper was not satisfied with the mere establish. ment of the material facilities for investigation which his gift of the laboratory afforded, but in association with Mr. John Garrett, of Baltimore, save a fund sufficient to carry on rasearches for several years, while a brother of the latter, Mr. Horatio Garrett, now deceased, provided a fund for a library. The Saranac Laboratory, as will be seen by the exterior view, is a substantial, fireproof, stone building, located near the Adirondack Cottage Sanitarium, which is a well resort for consumptives. It consists of one story and a basement. The interior is finished with white enameled brick wails, which permit of easy disinfection, while being simple and attractive. The laboratory, as will be noticed by the illustration on the front page, is spacious, has high ceilings, perfect light, and ventilation

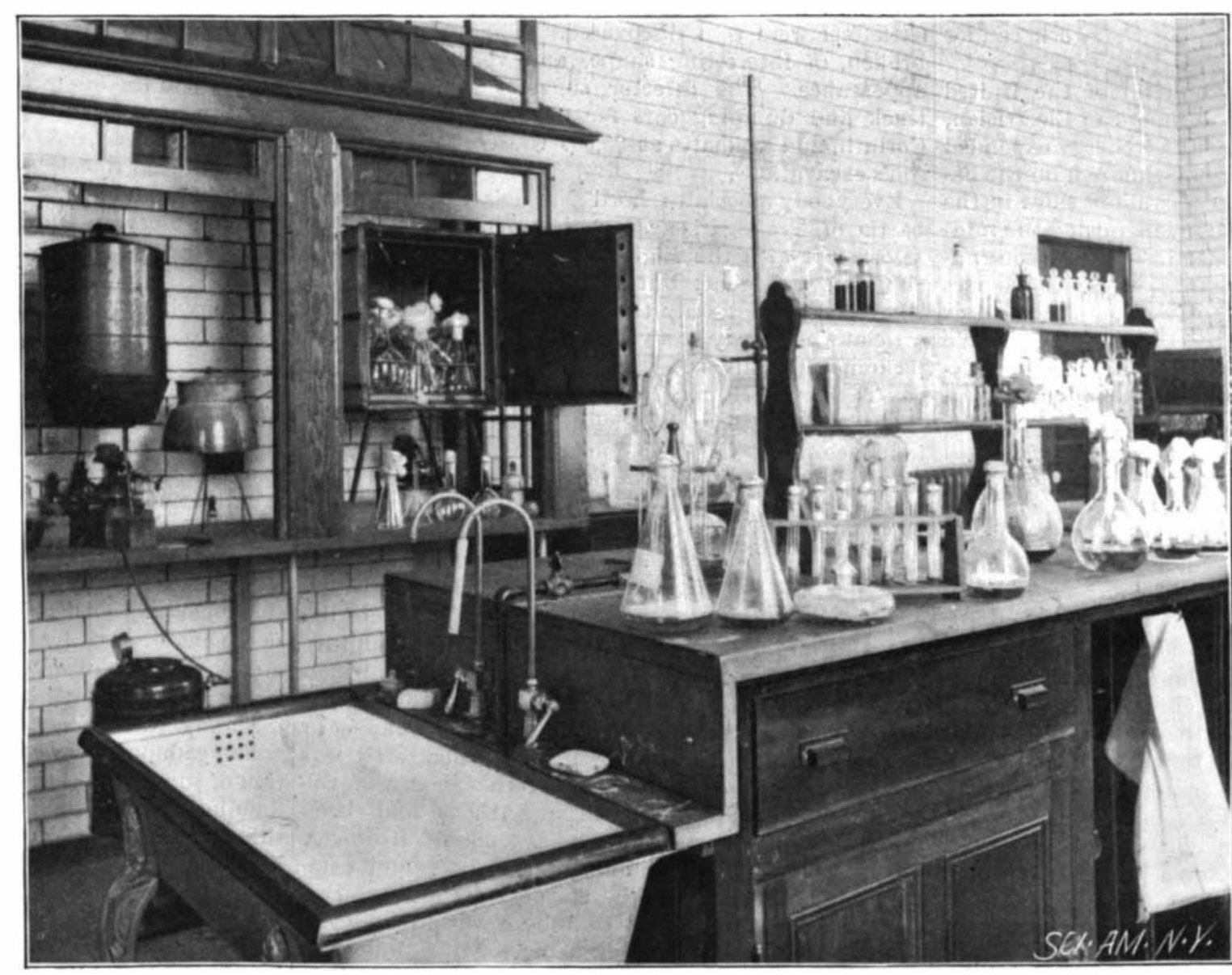

SARANAC LABORATORY-INTERIOR MAIN ROOM.

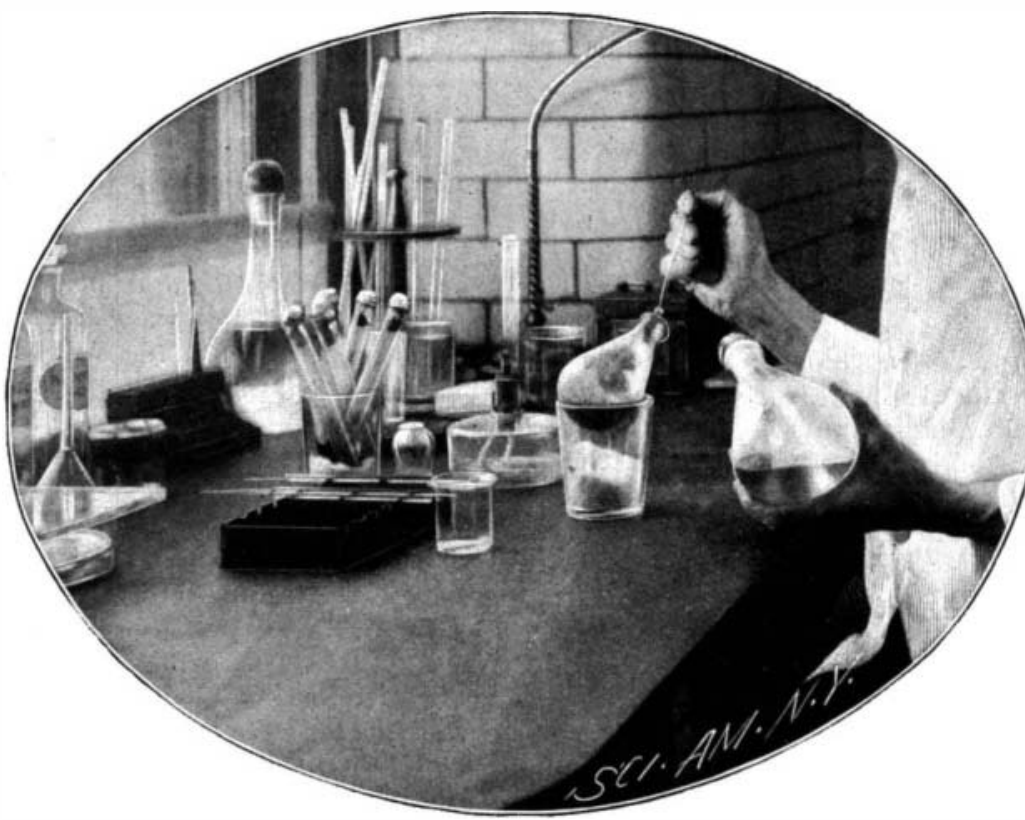
temperature, maintained by means of a lamp place under the thermostat. Overheating is prevented by an electrical alarm controlled by a thermometer. The whole is inclosed in an outer glass case with doors.

There are also two private workrooms besides a library specially devoted to the literature of tuberculosis, a room for aniwal examinations, and a room for living animals under observation in the basement. It is by the study of such growths or cultures that the life history of this sinister germ is made out and a clear understanding is obtained of its action in the human body. Through these cultures, also, studies can be carried on upon various agencies which it is hoped may be beneficial in the treatment of the disease.

The bacillus of tuberculosis is naturally treated with respect in this laboratory. Precautions against infection are constantly employed in handling flasks and other re ceptacles containing the bacilli. The same is true of the animals, whose cages are constructed of galvanized iron, so that they can cleansed. The aninal room, as well as the examination room, is occasionally flushed out with the hose, and sterilization by boiling is practiced on all apparatus before cleans-

Guinea pigs and rabbits are chiefly employed for experimental purposes and animal tests of many old and new remedies used in the treatment of tuberculosis form especially interesting branches of the work. New methods of treatment can be properly controlled only in this way, as it is impossible to secure uniform conditions in man and experience shows that deductions made from animals very generally apply to human beines. This feature renders the laboratory valuable to the neighboring sanitarium in thus bringing scientific method of diagnosis and treatment to the aid of the patients. The equipment of the Saranac Laboratory provides for a great variety of work on the subject of tuberculosis, and, although so much has been revealed through the labors of Koch and others, there still remains a wid field unexplored in this 
too familiar disease. There are many problems yet to be solved relating to public and private hygiene, in cluding the spread of tuberculosis in man and domestic animals. There are many less practical but still highly interesting questions concerning the biology of this parasite, its variations in virulence and poisonous products ; and, furthermore, the possibilities of alteration by changing its growth conditions.

There is great need for educational work in the matter of infection in tuberculosis, and it may be pertinent here to mention briefly some facts relating to it which have thus far been amply demonstrated

1 The sputum of consumptives is the source of infection in by far the greater proportion of cases.

2. The breath alone does not contain the bacillus.

3. Sunlight with drying destroys the vitality of the bacillus in twenty-four hours' exposure.

4. The bacilli in sputum may preserve vitality for months, when deposited in badly lighted and ill ventilated places.

It is worthy of note that victims of the disease usu ally have an acquired or inherited susceptibility. Direct inheritance of pulmonary tuberculosis is probably extremely rare.

Fig. 1 is a reproduction from photographs by Edward Leaming, M.D., made at the College of Physicians and Surgeons, New York, of bacilli magnified 1,000 diameters, found in the sputum of a person affected with tuberculosis. The minute elongated black specks, sometimes arranged to form the letters $\mathrm{V}$ and $\mathbf{X}$, are the bacilli, and are distinctive in shape, to be readily detected and recognized wherever seen when properly stained.

It can easily be comprehended from the photograph lt can ea ily be comprehended from the photograph in dust when deposited, is dried and pulverized.

The cultures of tubercle bacilli are comparable to the hothouse cultivations of many plants, though they require more delicately combined conditions for their development. They must have moisture, absence of light, and a fairly uniform temperature, near to that the human liody. A first culture of the bacillus

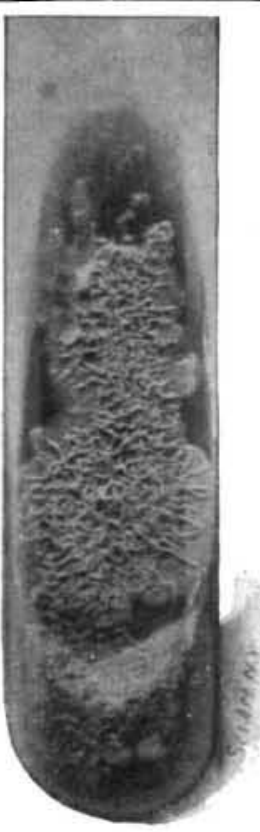
$\begin{array}{cc}\text { Fig. } 2 . & \text { Fig. } 3 . \\ \text { TUBE CULTURE } & \text { B. TUBERCULOSIS-CULTURE ON }\end{array}$

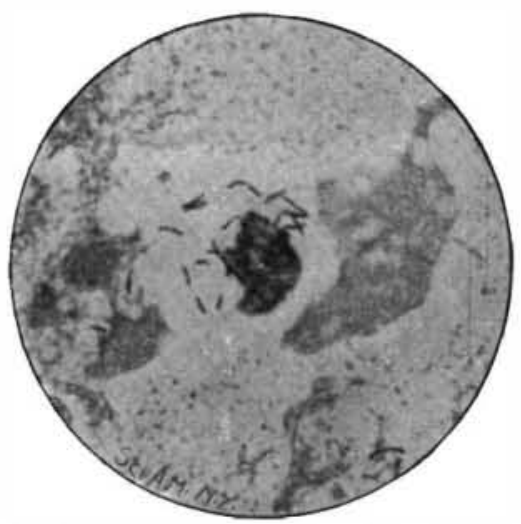

It is, in fact, very difficult to start cultures on any ther substance except potato.

Figs. 2 and 3 are excellent photographs showing the growth of these bacilli on agar agar or Japanese gelatin. After the artificial cultivations are started on serum or potato, it becomes fairly easy to continue rich growths on agar, beef broth, and even upon solutions of salts containing phosphates, sulphates, carbonates and glycerine. This is done by transplanting from an actively rowing culture a particle or flake of the crustlike mass of like neda. The detals of this process are Large numbers of fluid cultures are needed in the study of the growth products of the bacillus tuberculosis.

Tuberculin is made from flasks of bouillon grown six weeks, during which time the fluid becomes charged with the soluble products of growth. The original tuberculin of Koch, which caused so much excitement five years ago, consisted of such cultures simply evaporated to one-tenth their volume, and filtered free of bacilli.

Tuberculin, or the "lymph," is still used as a remedy in a very limited way, in spite of the condemation it receives as a consequence of unfortunate results in the past. A few selected cases are undoubtedly benefited by it, but by far the most important sphere of usefulness for tuberculin is for the diagnosis of tuberculosis. Its extensive employment for this purpose in cattle needs no mention, as its value is well established.

The use of tuberculin for detecting early tuberculosis in human beings is becoming more general, though the odium that was cast on it during its indiscriminate use four or five years a still clinss to it in the minds cour or five

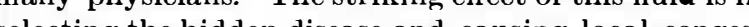
cocting the hidden disease and causing local congestion therein, while at the sane time producing const tutional disturbances such as fever, malaise and mus cular pains, all of which soon disappear. No effect follows in the great majority of persons when tuberculosis is absent.

Inasmuch as the successful arrest and cure of tuberculosis depend upon its early detection, we can no tuberculosis is one of

the most difficult of all

the most difficult of all the pathogenic germs following attempts to grow it from a tuberculous animal, or-what is still more difficultdirectly from the sputum of a consumptive. Such sputum usually contains numerous rapidly growing bacteria besides the slow grow-
ing tubercle bacillus, so that the tubes become that the tubes become contaminated e asily gets a start.

It is customary first to inoculate a suinea pig or a rabbit with a small particle of the expectoration, which expectoration, which, unless the anima shortly dies of septicæmia, quite uniformly results in death from tuberculosis after six weeks or within three months. From the diseased organs, and especially from the lymphatic slands, bits of tissue containing bailli are obtained tirely tirely free from other germs which were present in the inoculate sputum, but were unable to develop in the animal after a shor time, leaving the field clear, so to speak, for the tuberculosis These bits of tubercuare transferred on sterilized forceps and platinum needles to tubes of hardened blood serum, upon the surface of which they are rubbed.

Koch first succeeded in growing this germ upon coarulated blood upon coagulated bloo serum, which furnishes nutriment most nearly their natural pabulum.

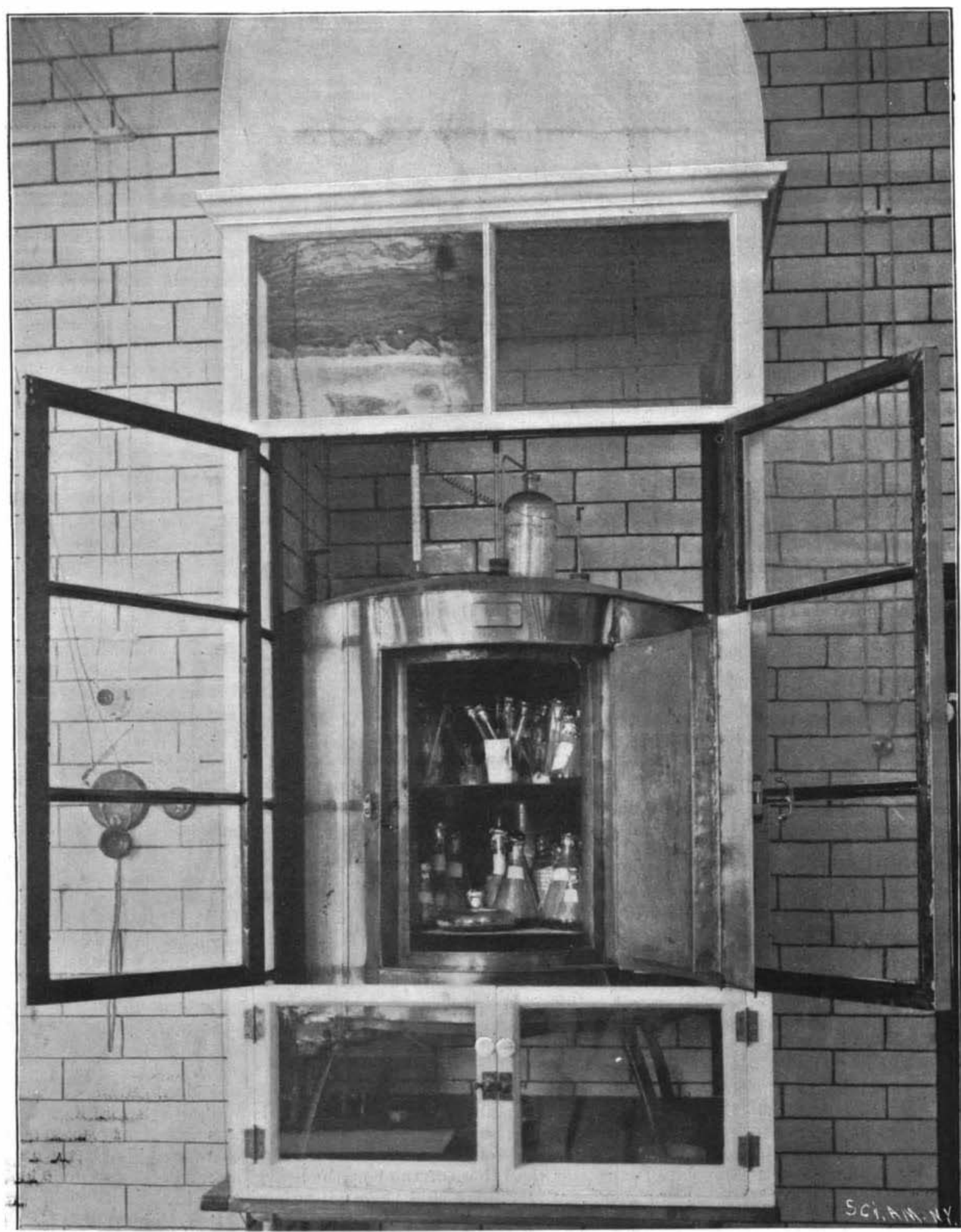

SARANAC LABORATORY-INCUBATOR OR CULTURE OVEN. lready revealed. I these alone are considered, we owe a great debt to Koch and his brilliant work.

There are three in valuable methods of diagnosis in obscure cases, which in the order of frequency of application are

1. The microscopical examination of sputum and other secretions for the presence of tubercle bacili.

2. The inoculation into susceptible animal of suspected sputum, etc., in which the microscope fails to revea the bacilli.

3. Tuberculin injection, where the first two methods fail, or there is no sputum or other discharge available for examination.

When the disease is present, it can be de tected in some one of these ways with almost absolute certainty, even in its earlier stages.

Probably the most iuportant problem or line of research engas ing the attention of la boratory workers in medicine at present is the subtle one of immunity from or acquire insusceptibility to tuberculosis and othe diseases. We canuot yet say whether we shall ever by artificial means be able to protect the human bod against the invasion and spread of the bacillus tuberculosis, yet we may cherish this possibility in view of the recent specific antitoxir o unquestionably useful in diphtheria. The discovery of a specific remedy for tuberculosi has always been the 
dream of enthusiasts, and it may be that ere long research will develop methods for the production of antitoxic serum efficacious in this disease. Experiments in this direction have thus far led to results not
without pronise, but as yet without any demonstrate practical value. It seems reasonable to expect the development of some means of neutralizing the poisonous products of the bacilli in the body, as has been done in

diphtheria, even if a complete cure be not thus effected.

When we consider the process accompanying natura recovery from consumption, which we call increase in resistance, the loss of which constitutes the main factor in susceptibility, we must conclude that the success of specific remedy involves many influences in our complex civilization which raise or lower bodily vigor; and that the permanence of any immunity produced must also depend on these factors. An open-air life in a favorable climate, combined with nutritious food, accomplishes than sure of consumption assist. The world will doubtless cling to such verities until science shall point out better methods, discovere until science shall point out bette

While state and national authorities are concerne with varying degrees of interest and success in furthe ing the economic interests involved in the prevention of diseases among cattle, the human animal in this country has as yet certainly been largely ignored in official measures for the public weal. Among the multitudes of safeguards now put about life, can we afford to neglect studies which look to the control of this widespread disease in man?

We are indebted to Mr. G. W. Baldwin, the photographer of Saranac Lake, for the excellent photographs from which our illustrations are made.

\section{The New Navy hill.}

Whatever regret may be caused in some quarters by the fact that the new navy bill as reported by the House Naval Committee makes no provision for the addition of any new battleships to those already built or building, one cannot but rejoice that the changed aspect of our international relations is in some measure the cause of the omission, the sense of the pressing need the cause of the omission, the sense of the pressing need ated with the return of tranquillity in our foreign relaated

The last naval bill with its large appropriation of over thirty millions was passed at a time when the political sky was overcast and possible complications with England and Spain were threatening. The intervening twelve months, thanks to skillful and well directed diplomacy, have seen a great clearing of the air, the effect of which is undoubtedly seen in the provisions of the present bill.

It is true that, as reported by the sub-committee, the bill recommends an even larger appropriation than last year, the total being $\$ 32,165,234$; but it must be borne in mind that although $\$ 13,146,155$ of this sum are asked for "increase of the navy," and for " armor and armament," a large proportion of the latter sum is for carrying on the construction of the five battleships which have recently been authorized and are now in the early stages of construction. There is no doubt that the fact of our having in all six first-class battleships under way has also tended to reduce the recommendations for new ships. Including the Iowa, now nearing completion, the battleships under construction have an aggregate displacement of 57,580 tons, and as will be seen from the details given below they will constitute a homogeneous fleet of practically the same size, speed, and fighting power :

The Iowa, of 11,300 tons displacement and 161/2 knots speed, carrying four 12 inch, eight 8 inch, and six 4 inch guns besides 26 smaller guns.

The Kearsarge and Kentucky, of 11,500 tons and 16 knots speed, carrying four 13 inch, four 8 inch, and fourteen 5 inch guns, the last being rapid-firers, with 20 smaller guns.

The three ships of the Alabama class, of 11,520 tons and 16 knots speed, carrying four 13 inch guns and fourteen 6 inch rapid-firers, with 28 smaller guns.

These ships, which should all be in commission within the next three or four years, will constitute a formidable addition to our first line of defense. Taken with which are of less displacement but greater offensive power, they will give the United States a fleet of nine power, they will give the United States a fleet of nine first-class battleships, admirably adapted by their simi-

At the same time it should be remembered that a naval preparation should be anticipatory, especially in the construction of battleships. With the plant that already exists in the country it would take at the very least three years to build and equip one of these floating fortresses, and not all the patriotism and wealth of the country could lessen the time of construction by an appreciable amount. The day when it was possible to "create" a navy passed away with the passing of the shipwright with his ax and his adz. Modern battle-
ships are no longer created : they are the result of a ships are no longer created; they are the result of a stead of months.
For this reason it would, perhaps, be a wise policy to institute a regular programme of shipbuilding, with provision for the regular addition of so much tonnage
each year. By such an arrangement the cost would be each year. By such an arrangement the cost would be
evenly distributed, the burden of it lightened, and the evenly distributed, the burden of it lightened, and the
nation would be saved from the dangers of panic expenditure on the one hand and of absolute neglect of the navy on the other.

Regarding the important question of the price of Regarding the important question of the

"In dealing with this question of cost, however, the mmittee has regarded it as one of such technical coracter that the information at its command is not ufficiently definite to enable it to fix with certainty a price per ton upon such a product
has been indisposed to do so."

A lump sum is provided for the purchase of armor for the three ships now building, and the maximum price of $\$ 400$ per ton named by the Secretary of the Navy is practically adopted. This figure must not be exceeded at the same time he is free to secure the armor at a wer price if he can do so.

Nobody will dispute the fact that "the question of cost" is one of a "technical character" any more than they will the fact that if American manufacturers have been selling Harveyized armor to the Russian
government for half the price they were charging the home government, the question of cost has a decidedly ommercial character as well. Granting that in the present emergency the suggestion of Secretary Herbert to be honts the best compromise that can be made, it is bill will receive in the House and Senate, the actual bill will receive in the House and Senate, the actual
facts regarding the Russian order and the cost of facts regarding the Russian order and the cost of
manufacturing armor plate in this country will be established.

\section{A "PHONENDOSCOPE" OR IMPROVED} PHONOSTETHESCOPE.

A simple device for rendering distinctly audible on a agnified scale small sounds in the human body, or in

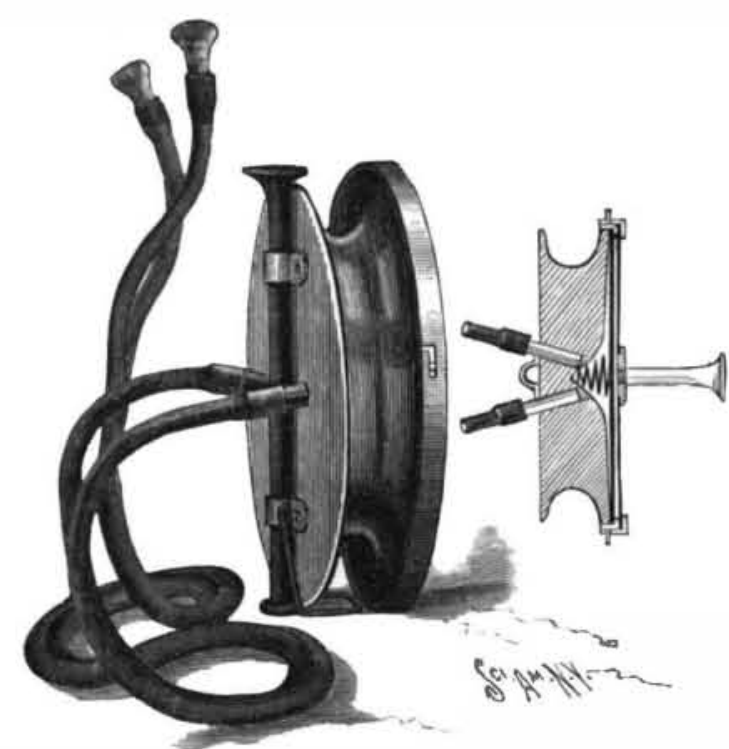

THE BAZZI AND BIANCHI "PHONENDOSCOPE."

odies in general, is represented in section and in perpective in the accompanying illustration. It was patented by Eugenio Bazzi and Aurelio Bianchi, of
Florence, Italy, in several Eurcpean countries, in 1895, and a patent therefor has recently been issued in the United States. The improvement is based essentially with a body of larger mass and greater inertia, when laid upon another body in which small sounds occur, cause a vibratory action to be set up in the membrane, while the large mass of the heavy solid body is but very slightly or imperceptibly affected. As shown in the sectional view, the inert disk of heavy metal or weighted wood has a central hollow cavity covered by
a membrane of hard rubber or similar material constituting a diaphragm, and inside the space thus forme is a weak spring pressing upon the diaphragm. The membrane is packed tightly against the edge of the somewhat thicker hard rubber plate, which preferably has a central orifice where may be secured a hard rubhas a central orifice where may be secured a hard rub-
ber or metal rod, which, when not in use, may be detachably fastened on the rear side of the instrument. In the rear of the disk are two holes which terminate in the central hollow, and here are inserted hearing
trumpets or flexible tubes leading to the ears of one using the instrument, when the latter has been placed
un in position where the sounds to be noted or detected are looked for. Either the knob on the end of the rod, or
the hard rubber outer plate of the instrument, is placed in contact with the body where the sounds are expected, and the tone vibrations cause moveruents of
the plate far greater than those of the box, the heavy the plate far greater than those of the box, the heavy
disk being comparatively inert, and these vibrations disk being comparatively inert, and these vibrations
are communicated to the sense of hearing through the connected tubes.

\section{GRANT'S MACHINE FOR SOLVING NOMERICAL} ALGEBRAIC EQUATIONS.

There is no branch of algebra upon which more labor has been spent than upon the "theory of equations," which treats mainly of the determination of the roots of equations of the form

$$
a x^{5}+b x^{4}+c x^{3}+d x^{2}+e x+f=0
$$

and Sturm's theorem is the only complete solution of the difficult problem of finding the roots of such equations when their coefficients are numerical. To quote Prof. David E. Smith, a recent writer on the history of mathematics, "All processes were, however, exceedingly cumbersome until Sturm (1829) communicated to the French Academy the famous theorem
which bears his name and which constitutes one of the most brilliant discoveries of algebraic analysis. But there is more than one way to look at almost any subject, and this paper is to describe a machine to determine these roots approximately with but the least amount of assistant calculation.

The object is to discover the numerical values, called "roots," which, substituted for the unknown quantity, in any numerical example, such as $7 \mathrm{x}^{3}+3 \mathrm{x}^{2}-15 \mathrm{x}-4$ $=0$ for example, will satisfy that equation and reduce it to zero. Theoretically, Sturm's theorem will completely determine all the real roots, but that method is o difficult to apply to decimal fractions that it is always abandoned after the integers have been discovered, and the solution completed by some other process. The machine is subject to a similar delicate and costly description, it will give roots that are reliable only to one or two decimal places. It is, therefore, like Sturm's theorem, a means for so far locating the roots that they may be worked, if required to be very accurate, by some such rule as Horner's method.

There are two sets of scale beams, one more in number than the degree of the largest equation the machine is required to solve. Half of these beams are pivoted to balance on a fixed post and the other half are mounted on a movable post. On each beam is a coefficient weight which may be set in either positive or negative position on it by means of a scale of coefficients. The por shown by a scale of roots. Thisis essentially the whole machine, although work

An examination of the engraving will show that it is a multiplying weighing machine,each beam being coupled to the next, so that the effect is continually multiplied. When all the pins are in the same vertical line the multiplier is unity, and when each pin is at the fulcrum of the beam it is working in the multiplier is infinity. Between these two points, unity and infinity, the multiplier is the proportion of the fixed distance of the pin from the fulcrum of its own beam to its variable distance from the fulcrum of the beam it is working in. This proportion, which is denoted by $\mathbf{x}$, is uniform for all the beams for the same position of the movable post. If the weight on the lower beam be set at any figure on its scale denoted by " $\pm \mathrm{a}$," the effect on the second beam will be " \pm ax," for the effect of the weight on its own beam at the unity point is indicated by the scale, and that effect is multiplied by $\mathbf{x}$ at the unity point of the next beam. As the second beam has a weight set the total effect on that beam will be " $\pm \mathrm{ax} \pm \mathrm{b}$." This, in turn, is transmitted to the third beam and multiplied by $\mathrm{x}$ as well as added to the weight " $\pm \mathrm{c}$ " on that beam. making the total effect " $a x^{2} \pm b x \pm c . "$ Similarly, the effect on the fourth beam is " $\pm a^{3} \pm b^{2} \pm$
$c x \pm d, "$ and so on as far as the system extends. That being the compound effect of the weights acting on each other in succession, it is seen that the six beams will balance only wh
fect is zero, that is, when

$$
\pm a x^{5} \pm b x^{4} \pm c x^{3} \pm d x^{2} \pm e x \pm f=0
$$

and that is the algebraic equation of the fifth degree in its most general form. Therefore, if the coefficient weights be set in their several positions and the post then show the proportion $x$ and solve the of roots will The machine as here shown will directly find only theroots situated between unity and infinity, both pos ive. If the slot is continued past the fulcrum, toward the negative end of its beam, the machine will find negative roots also, but it is much more practicable to imply shift the weights on the fixed post each to the same reading at the other end of its beam, thereby changing the signs of all the roots of the equation and enabling the negative ones to be determined as if they were positive. If the slot is continued beyond the unity point the machine will find roots smaller than it is necessary to make a separate search for any roots there may be between plus unity and minus unity, after so transforming the equation as to shift all of its after so transforming the equation as to shift
roots in the positive direction two integers.

It is plain that if a weight is set at 0 , or taken of its beam, that coefficient is 0 , so that the machine will 


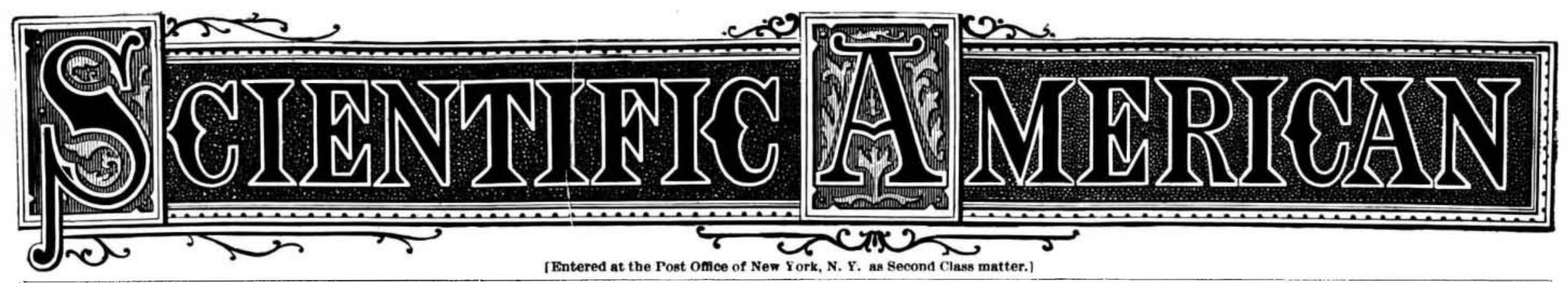

A WEEKLY JOURNAL OF PRACTICAL INFORMATION, AR'T, SCIENCE, MECHANICS, CHEMIST'RY, AND MANUFACTURES.

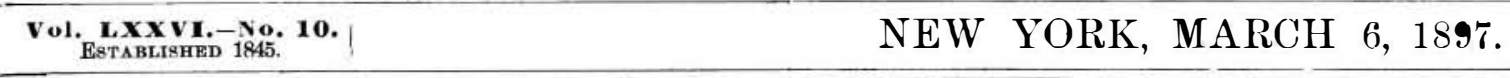
$\left[\begin{array}{l}\$ 3.00 \text { WEERLY. } \\ \text { A YAR. }\end{array}\right.$

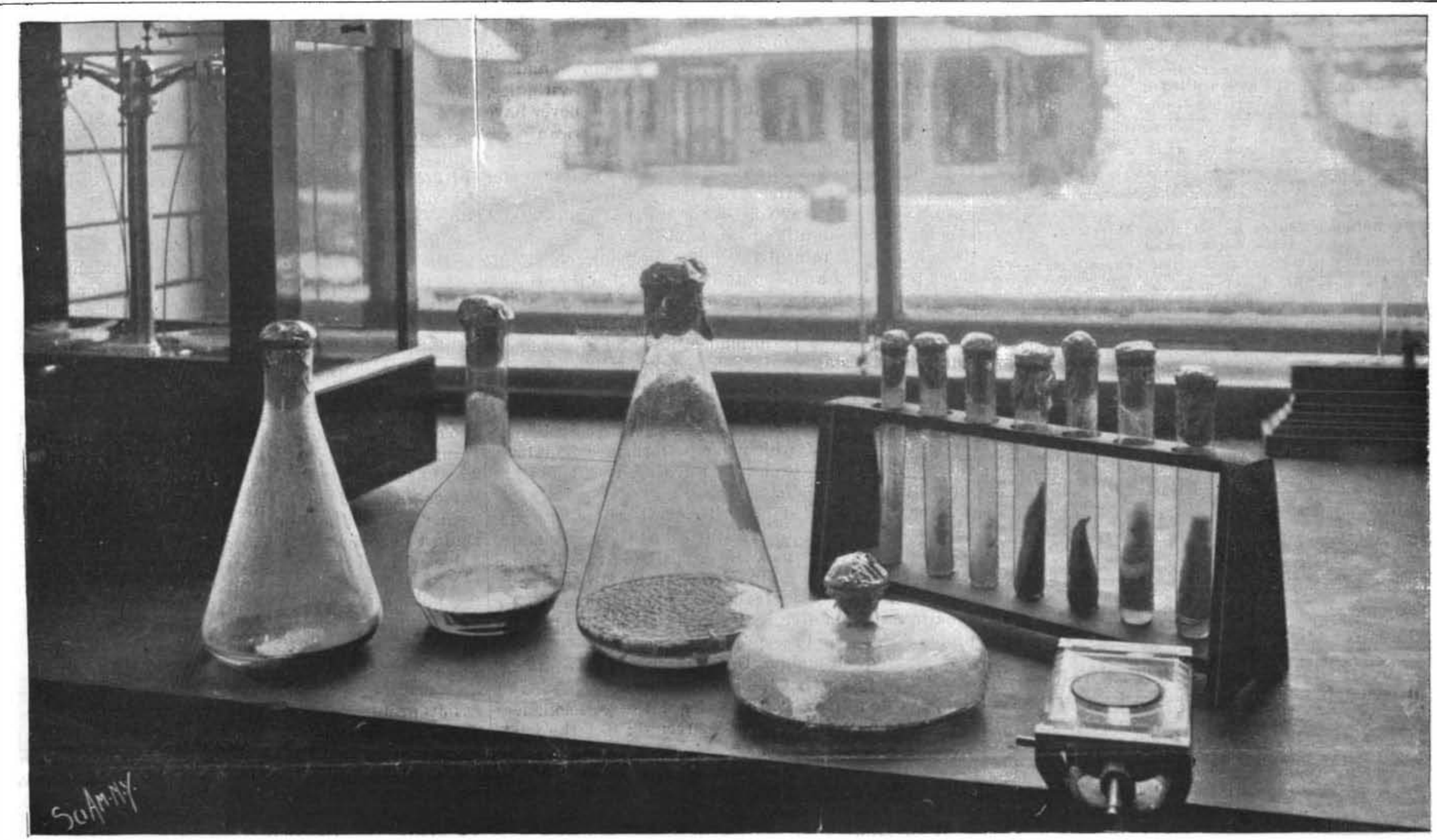

CULTURES OF BACILLI TUBERCULOSIS.

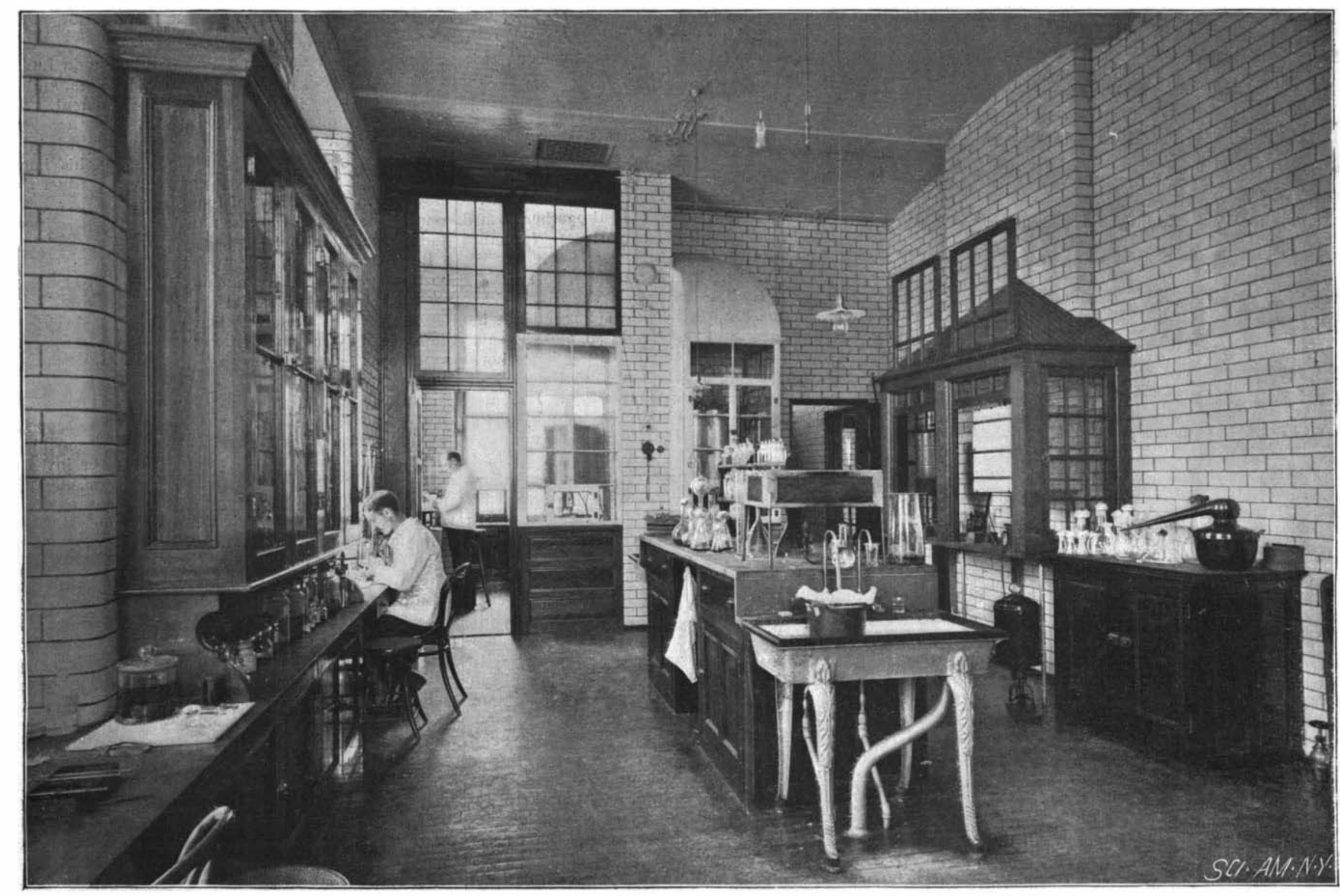

LABORATORY AT SARANAC LAKE, N. Y., FOR THE STUDY OF TUBERCULOSIS-INTERIOR OF MAIN RO0M.-[See page 152.] 